\title{
SEASON AND LANDSCAPE WISE DISTRIBUTION OF BUTTERFLIES IN TAMHINI, NORTHERN WESTERN GHATS, INDIA
}

\author{
A.D. Padhye ${ }^{1}$, Neelesh Dahanukar ${ }^{2}$, Mandar Paingankar ${ }^{3}$, Madhura Deshpande ${ }^{4}$ and Deepti Deshpande ${ }^{5}$ \\ 1, 2 Department of Zoology, Abasaheb Garware College, Karve Road, Pune, Maharashtra 411004, India. \\ ${ }^{3}$ Department of Zoology, University of Pune, Pune, Maharashtra, India; ${ }^{4}$ Biometry and Nutrition Building, Agharkar Research Institute, Agharkar \\ Road, Pune, Maharashtra, India; ${ }^{5}$ 334, Plant Science Building, Department of Plant Pathology, Cornell University, Ithaca, New York 14853 , USA. \\ Email: ${ }^{1}$ adpadhye@yahoo.co.uk
}

\begin{abstract}
Our study takes the first step of documenting butterfly diversity and distribution along the seasonal gradient and across five landscape elements. We censused butterfly community in Tamhini, northern Western Ghats, across six seasons and five landscape elements using line transect method for two years. A total of 69 butterfly species belonging to 52 genera and five families were encountered in the study area. The data was analysed for $\alpha$ and $\beta$ diversity. There were two peaks in the $\alpha$ diversity in summer and early winter. Monsoon fauna was distinctly different from that of other seasons. Maximum diversity was observed in the partially disturbed areas with human habitation. Landscape type satisfying variable niche showed maximum $\alpha$ diversity. Our findings in the seasonal and landscape wise distribution of butterflies are important with respect to monitoring animal diversity and defining conservation strategies in the northern Western Ghats.
\end{abstract}

\section{KEYWORDS}

$\alpha$ and $\beta$ diversity, butterfly, distribution, landscape, Lepidoptera, seasonal distribution, Western Ghats

Mapping, monitoring, management and conservation of biological resources have attracted major attention in the recent years, as depleting biodiversity, unlike any other environmental threat, is irreversible. Myers et al. (2000) had identified 25 biodiversity hotspots from all over the globe, which need immediate attention with the view of biodiversity conservation. The Western Ghats of India is one of the hottest hotspots, however, its biodiversity is under threat due to deforestation (Myers, 1990). Thus, to assess and measure the biological diversity in Western Ghats so as to design and implement potent conservation strategies, Western Ghats Biodiversity Network (WGBN) organised a programme of sampling species level diversity in a number of taxonomic orders in 25 different localities distributed over the length of Western Ghats (Gadgil, 1996). The current study is a part of the same programme.

As it is impractical to monitor each and every taxon, some of the key or focal taxa play a vital role in biodiversity monitoring studies. Butterflies are an excellent choice in this respect (Kunte et al., 1999). They are common almost everywhere, attractive and easy to observe. Many species, both common and rare, can be reliably identified in the field, without killing the individuals, with the help of available field guides. As many species are strictly seasonal and prefer only particular set of habitats (Kunte, 1997), they are good indicators of habitat quality (Kocher \& Williams, 2000). Butterflies and their caterpillars are dependent on specific host plants for foliage, nectar and pollen as their food. Thus, butterfly diversity indirectly reflects overall plant diversity, especially that of herbs and shrubs, in the given area. Change in land use pattern leads to landscape changes that can reflect change in butterfly diversity and distribution. In the Western Ghats, such changes in landscape are taking place at a large scale (Jha et al., 2000). Hence, this type of study is essential in conservation and management of the Western Ghats biodiversity.

Efforts in monitoring butterfly diversity in the Western Ghats have increased recently with several studies published recently (Ambrose \& Raj, 2005; Arun, 2003; Babjan \& Archana, 1999; Baskaran \& Solaiappa, 2002; Bhalodia et al., 2002; Borkar \& Komarpant, 2004; Eswaran \& Pramod, 2005; Gunathilagaraj et al., 1997; Kunte, 1997, 2001; Nair, 2002, 2003; Radhakrishnan, 2000). However, most of these studies are qualitative which gives checklist, seasonality and relative abundance based on presence/absence data. We have, therefore, conducted the surveys to know the butterfly diversity in this locality by using quantitative techniques. The data were analysed to understand the $\alpha$ - and $\beta$-diversity across the six seasons and five different landscape elements (LSE). We have also studied seasonal distribution- and LSE-wise and abundance patterns in the butterfly community of this area. This was ultimately to understand the conservation priorities in the northern parts of Western Ghats.

\section{Study Site}

Tamhini $\left(18^{0} 27^{\prime} \mathrm{E} \& 73^{0} 25^{\prime} \mathrm{N}\right)$ is a small village in Maharashtra situated in the northern Western Ghats. The average altitude of the village and its surrounding area is $600 \mathrm{~m}$, while the surrounding hilltops have altitude ranging from 850 to $1050 \mathrm{~m}$. The $25 \mathrm{~km}^{2}$ area that we monitored totally, included four other small villages namely Nivewadi, Sarole, Dhangarwadi, and Dongarwadi. Some part of the study area, especially around the villages, is private farmland. Some mountain slopes bear reserved forests of the forest department of Maharashtra. Climatic conditions of this area are typically tropical. The dense forest areas are humid throughout the year where the relative humidity ranges between $70 \%$ in summer to almost $100 \%$ in monsoon. The annual rainfall is from 5500 to $6500 \mathrm{~mm}$. Average minimum and maximum temperatures range between $15^{\circ}-25^{\circ} \mathrm{C}$. The minimum temperature sometimes drops to even less than $10^{\circ} \mathrm{C}$ while the maximum shoots up to $30^{\circ} \mathrm{C}$.

Manuscript 1142: Received 03 August 2005; Revised received 14 January 2006: Finally accepted 09 Febuary 2006; Date ou publication 21 Februry 2006 March 2006 | ISSN 0973-2535 (Print edition); 0973-2551 (Online edition) 


\section{Methodology}

\section{Data collection}

Five line transects were set up, which were approximately $500 \mathrm{~m}$ long and $10 \mathrm{~m}$ wide, passing through the five landscape element types. The transect lines were walked at a constant pace for for approximately half an hour. Transects were walked from 0730 to $1100 \mathrm{hr}$, when butterflies are most active. Transects were walked every month from October 1998 to September 2000. Butterflies were identified in the field with the help of field guides (Gunathilagaraj et al., 1998; Kunte, 2000). Specimen collection was strictly avoided. This may have resulted in minor error in field identification of some of the small sized species. For the interpretation of collected data the year was divided into six seasons as per Kunte (1997). These seasons are (i) Spring - February and March; (ii) Summer - April and May; (iii) Early monsoon - June and July; (iv) Late monsoon - August and September; (v) Early winter - October and November and (vi) Late winter - December and January. Furthermore, each transect line was also categorised in one of the five landscape elements, viz. evergreen forest (LSE 1); ragi shift cultivation (scrubland subjected to slash and burn activity) (LSE 2); riparian (LSE 3); grassland (LSE 4) and paddy fields with human habitation (LSE 5). The population fluctuation in butterfly species across seasons and across landscape elements was studied by preparing simple matrix with species in column and season or landscape elements in row (Appendix I). The taxonomic status of butterflies is adapted from Kunte (2000).

\section{Statistical analysis}

In order to estimate total number of species that could be present in the study area, we constructed species individual curves using data gathered through transects. Cumulative number of species recorded was plotted against the number of individuals seen. We fitted Michaelis - Menten equation, given by $\mathrm{S}=\mathrm{S}_{\mathrm{m}}$ $\mathrm{N} /\left(\mathrm{K}_{\mathrm{m}}+\mathrm{N}\right)$ where, $\mathrm{S}$ is the cumulative number of species, $\mathrm{N}$ is the number of individuals, $\mathrm{S}_{\max }$ is the maximum number of species that could be present and $\mathrm{K}_{\mathrm{m}}$ is the Michaelis-Menten constant (Paranjape \& Gore, 1997).

Margalef's species richness index was used to compare species richness across seasons and across landscape elements. The index is calculated using the equation $\mathrm{R}=(\mathrm{S}-1) / \ln \mathrm{N}$, where $\mathrm{S}$ is the number of species, $\mathrm{N}$ is the total number of individuals (Magurran, 1988).

The $\alpha$-diversity of butterfly species across seasons and across landscape element was calculated using Shannon index of diversity given by the equation, $\mathrm{H}^{\prime}=\Sigma$ pi $(\ln \mathrm{pi})$, where, $\mathrm{pi}=\mathrm{ni}$ / $\mathrm{N}$; ni is the number of individuals of $\mathrm{i}^{\text {th }}$ species and $\mathrm{N}=\Sigma \mathrm{ni}$ (Magurran, 1988).

To calculate whether species are distributed evenly across seasons and across landscape elements, evenness index was used which is given by the equation, $\mathrm{E}=\mathrm{H}^{\prime} / \mathrm{ln} \mathrm{S}$ (Magurran, 1988).

The $\beta$-diversity, which represents unshared species, was measured by finding similarity or overlap between butterfly species composition across seasons and across LSE types. Both qualitative data (presence or absence of species) and quantitative data (presence or absence of species along with the number of individuals belonging to each species) were used to calculate percent similarity, using Bray Curtis similarity index (McAleece, 1998). Dendrograms were prepared to understand seasonal and LSE wise trends.

\section{Results}

During the transect sampling, we recorded a total of 58 species as compared with 331 species of butterflies recorded from entire Western Ghats (Gaonkar, 1996). Out of these 58 species, 56 belong to 43 genera and five families (Table 1) while two species were unidentified. Visual search revealed 11 species outside transect areas (Table 2). Therefore, a total of 69 identifiable butterfly species were recorded from this area during the study.

From model fitted to species accumulation curve (Fig. 1), $\mathrm{S}_{\text {max }}$ estimate suggests that there could be at least 65 species in the study area. This estimate is close to our record of 69 butterfly species from this area. The percentage abundance of each species within the transects is given in Table 1. The species abundance curve (Fig. 2) shows a log series distribution where the number of rare species (Frequency of occurrence $\leq 8$ ) is more $(70 \%)$ and the number of abundant species (Frequency of occurrence $>8)$ is less $(30 \%)$. This indicates an uneven species distribution.

\section{Seasonal distribution}

Number of species, number of unique species, number of individuals, richness index, Shannon index and evenness index for six seasons is given in Table 3. The maximum number of species as well as maximum number of individuals was recorded in early winter. Species unique to particular season were maximum in early winter and summer. The species richness index shows high values in early winter and summer. Similar trend was observed for Shannon diversity index. The evenness index of species distribution was maximum in summer and minimum in late monsoon.

Cluster analysis of species composition in various seasons done from qualitative data (Fig. 3A) and quantitative data (Fig. 3B) revealed distinct trends showing difference in the clades. The overlap between different seasons predicted by quantitative data is far lesser than that predicted by qualitative data.

\section{Landscape element wise distribution}

Table 4 gives the number of species, number of unique species, number of individuals, richness index, Shannon index and evenness index for five landscape elements. The maximum species were recorded in LSE 5 followed by LSE 2. While maximum number of individuals were recorded in LSE 5 followed by LSE 1. LSE 5 showed maximum number of unique species. Maximum species richness and Shannon diversity index was seen in LSE 5 and LSE 2. However, evenness index is high in LSE 3 . 
Table 1. List of butterflies encountered during transects and their season and LSE wise distribution and aggregation along with the percentage abundance.

\begin{tabular}{|c|c|c|c|c|c|c|c|c|c|c|c|c|c|}
\hline \multirow{2}{*}{$\begin{array}{l}\text { Family / Species * } \\
\text { Nymphalidae }\end{array}$} & \multirow[t]{2}{*}{ Common name } & \multicolumn{6}{|c|}{ Seasons observed \# } & \multicolumn{5}{|c|}{ LSE typesobserved ** } & \multirow{2}{*}{$\begin{array}{l}\text { Percentage } \\
\text { abundance }\end{array}$} \\
\hline & & & & & & & & & & & & & \\
\hline Ariadine merione & Common Castor & $\mathrm{Sp}$ & - & - & - & Ew & - & 1 & - & - & - & 5 & 0.32 \\
\hline Cyrestis thyodamas & Common Map & - & - & - & - & Ew & - & - & - & - & - & 5 & 0.16 \\
\hline Danaus chrysippus & Plain Tiger & $\mathrm{Sp}$ & $\mathrm{Su}$ & - & - & Ew & $\mathrm{Lw}$ & 1 & 2 & 3 & 4 & 5 & 1.26 \\
\hline Danaus genuta & Stripped Tiger & Sp & $\mathrm{Su}$ & - & - & - & Lw & - & 2 & - & - & 5 & 0.47 \\
\hline Euploea core & Common Indian Crow & Sp & $\mathrm{Su}$ & - & $\mathrm{Lm}$ & Ew & $\mathrm{Lw}$ & 1 & 2 & - & 4 & 5 & 7.27 \\
\hline Euthalia garuda & Common Baron & - & $\mathrm{Su}$ & - & - & Ew & - & - & 2 & - & 4 & - & 0.32 \\
\hline Hypolimnas bolina & Great Egg Fly & - & Su & - & - & Ew & - & - & - & - & - & 5 & 0.32 \\
\hline Hypolimnas misippus & Danaid Egg Fly & $\mathrm{Sp}$ & - & - & - & Ew & - & 1 & - & - & 4 & 5 & 0.47 \\
\hline Junonia almana & Peacock Pansy & $\mathrm{Sp}$ & - & - & $\mathrm{Lm}$ & Ew & $\mathrm{Lw}$ & 1 & 2 & - & 4 & 5 & 0.79 \\
\hline Junonia hierta & Yellow Pansy & - & Su & - & - & - & - & - & - & - & - & 5 & 0.16 \\
\hline Junonia lemonias & Lemon Pansy & $\mathrm{Sp}$ & Su & $\mathrm{Em}$ & - & Ew & $\mathrm{Lw}$ & 1 & 2 & 3 & 4 & 5 & 2.53 \\
\hline Junonia orithya & Blue Pansy & - & - & - & - & - & $\mathrm{Lw}$ & 1 & - & - & - & - & 0.63 \\
\hline Kallima horsfieldi & Indian Blue Oakleaf & - & $\mathrm{Su}$ & $\mathrm{Em}$ & $\mathrm{Lm}$ & Ew & - & - & 2 & - & - & 5 & 0.95 \\
\hline Melanitis leda & Common Evening Brown & $\mathrm{Sp}$ & $\mathrm{Su}$ & - & - & Ew & - & 1 & 2 & 3 & - & 5 & 1.42 \\
\hline Mycalesis perseus & Common Bush Brown & - & $\mathrm{Su}$ & - & - & Ew & - & - & - & - & - & 5 & 0.63 \\
\hline Neptis hylas & Common Sailor & Sp & Su & - & - & Ew & $\mathrm{Lw}$ & - & 2 & 3 & 4 & 5 & 3.95 \\
\hline Parantica aglea & Glassy Tiger & Sp & - & $\mathrm{Em}$ & $\mathrm{Lm}$ & Ew & Lw & 1 & 2 & 3 & 4 & 5 & 6.48 \\
\hline Phalanta phalanta & Common Leopard & Sp & Su & $\mathrm{Em}$ & $\mathrm{Lm}$ & Ew & Lw & 1 & 2 & 3 & - & 5 & 2.21 \\
\hline Polyura athamas & Common Nawab & - & - & - & - & - & $\mathrm{Lw}$ & 1 & - & - & - & - & 0.16 \\
\hline Precis iphita & Chocolate Pansy & $\mathrm{Sp}$ & Su & $\mathrm{Em}$ & $\mathrm{Lm}$ & Ew & $\mathrm{Lw}$ & 1 & 2 & - & 4 & 5 & 5.69 \\
\hline Tirumala limniace & Blue Tiger & Sp & Su & - & - & - & Lw & 1 & 2 & - & 4 & 5 & 1.26 \\
\hline Ypthima asterope & Common Three Ring & - & - & - & - & Ew & - & - & - & - & - & 5 & 0.16 \\
\hline Ypthima baldus & Common Five Ring & - & - & - & - & Ew & $\mathrm{Lw}$ & 1 & 2 & - & 4 & 5 & 3.00 \\
\hline Ypthima hiiebneri & Common Four Ring & - & - & $\mathrm{Em}$ & $\mathrm{Lm}$ & Ew & $\mathrm{Lw}$ & - & 2 & - & 4 & 5 & 10.74 \\
\hline \multicolumn{14}{|l|}{ Papilionidae } \\
\hline Pachliopta aristolochiae & Common Rose & $\mathrm{Sp}$ & - & - & - & - & Lw & 1 & - & - & - & 5 & 0.32 \\
\hline Pachliopta hector & Crimson Rose & - & Su & - & - & - & - & - & 2 & - & - & - & 0.16 \\
\hline Papilio demoleus & Lime Butterfly & - & $\mathrm{Su}$ & - & - & - & - & - & 2 & - & - & 5 & 0.79 \\
\hline Papilio heleiu & Red Helen & - & $\mathrm{Su}$ & - & - & Ew & - & - & - & - & 4 & 5 & 0.47 \\
\hline Papilio polymnestor & Blue Mormon & $\mathrm{Sp}$ & $\mathrm{Su}$ & - & $\mathrm{Lm}$ & Ew & $L w$ & 1 & 2 & - & 4 & 5 & 3.48 \\
\hline Papilio polytes & Common Mormon & Sp & $\mathrm{Su}$ & - & - & - & $\mathrm{Lw}$ & 1 & 2 & 3 & 4 & 5 & 1.42 \\
\hline \multicolumn{14}{|l|}{ Pieridae } \\
\hline Anaphaeis aurota & Pioneer & - & Su & - & - & - & - & - & - & - & - & 5 & 0.16 \\
\hline Catopsilia pomona & Common Emigrant & $\mathrm{Sp}$ & $\mathrm{Su}$ & - & - & Ew & $\mathrm{Lw}$ & 1 & 2 & 3 & 4 & 5 & 3.79 \\
\hline Catopsilia pyranthe & Mottled Emigrant & - & $\mathrm{Su}$ & - & - & Ew & - & - & - & - & 4 & 5 & 0.32 \\
\hline Cepora nerissa & Common Gull & - & - & - & - & Ew & - & - & - & - & - & 5 & 0.47 \\
\hline Delias eucharis & Common Jezebel & $\mathrm{Sp}$ & Su & - & - & - & $\mathrm{Lw}$ & 1 & 2 & - & 4 & 5 & 1.11 \\
\hline Eurema hecabe & Common Grass Yellow & $\mathrm{Sp}$ & Su & $\mathrm{Em}$ & $\mathrm{Lm}$ & Ew & $\mathrm{Lw}$ & 1 & 2 & 3 & 4 & 5 & 8.69 \\
\hline Hebomoia glaucippe & Great Orange Tip & - & - & - & $\mathrm{Lm}$ & - & - & - & - & - & - & 5 & 0.16 \\
\hline Ixias marianne & White Orange Tip & - & Su & - & - & - & - & - & 2 & - & - & - & 0.16 \\
\hline Leptosia nina & Psyche & - & - & - & - & Ew & - & - & - & - & - & 5 & 0.32 \\
\hline Pararonia valeria & Common Wanderer & - & - & - & $\mathrm{Lm}$ & Ew & Lw & - & 2 & 3 & 4 & 5 & 1.74 \\
\hline Pieris canidia & Indian Cabbage White & $\mathrm{Sp}$ & - & - & - & - & $\mathrm{Lw}$ & - & 2 & 3 & - & 5 & 1.11 \\
\hline \multicolumn{14}{|l|}{ Lycaenidae } \\
\hline Abisara echerius & Plum Judy & $\mathrm{Sp}$ & $\mathrm{Su}$ & $\mathrm{Em}$ & $\mathrm{Lm}$ & Ew & $\mathrm{Lw}$ & 1 & 2 & 3 & 4 & 5 & 5.69 \\
\hline Caleta caleta & Angled Pierrot & - & $\mathrm{Su}$ & - & $\mathrm{Lm}$ & Ew & $\mathrm{Lw}$ & 1 & 2 & 3 & 4 & 5 & 2.53 \\
\hline Castalius rosimon & Common Pierrot & - & $\mathrm{Su}$ & - & - & - & - & - & - & - & - & 5 & 0.16 \\
\hline Euchrysops cnejus & Gram Blue & $\mathrm{Sp}$ & $\mathrm{Su}$ & - & - & Ew & $\mathrm{Lw}$ & 1 & 2 & 3 & 4 & 5 & 11.37 \\
\hline Jamides bochus & Dark Cerulean & - & - & - & - & Ew & - & - & 2 & - & - & - & 0.16 \\
\hline Jamides celeno & Common Cerulean & - & - & $\mathrm{Em}$ & - & Ew & - & - & 2 & - & - & 5 & 1.58 \\
\hline Nacaduba nora & Line Blue & $\mathrm{Sp}$ & - & - & - & Ew & - & 1 & - & - & 4 & - & 0.63 \\
\hline Talicada nyseus & Red Pierrot & - & $\mathrm{Su}$ & - & - & - & - & - & - & - & - & 5 & 0.16 \\
\hline \multicolumn{14}{|l|}{ Hesperidae } \\
\hline lambrix salsala & Chestnut Bob & - & - & - & $\mathrm{Lm}$ & - & - & - & - & - & - & 5 & 0.16 \\
\hline Odontoptilum angulata & Chestnut Angle & - & - & - & - & Ew & Lw & - & 2 & - & - & - & 0.32 \\
\hline Pseudocoladenia indrani & Tricoloured Pied Flat & - & - & - & - & Ew & - & - & 2 & - & - & - & 0.16 \\
\hline Spialia galbe & Indian Skipper & - & $\mathrm{Su}$ & - & - & - & - & - & 2 & - & - & - & 0.16 \\
\hline Tagiades litigiosa & Water Snow Flat & - & - & - & - & Ew & - & - & 2 & - & - & - & 0.32 \\
\hline Taractrocera ceramas & Tamil Grass Dart & - & - & - & $\mathrm{Lm}$ & - & - & - & - & - & - & 5 & 0.16 \\
\hline Udaspes folus & Grass Demon & - & - & - & $\mathrm{Lm}$ & - & - & - & - & - & - & 5 & 0.16 \\
\hline \multicolumn{14}{|l|}{ Unidentified } \\
\hline Species 1 & ? Black with red spots & - & - & - & - & Ew & - & - & - & - & 4 & - & 0.16 \\
\hline Species 2 & ? Yellow & - & - & $\mathrm{Em}$ & - & - & - & - & 2 & - & - & - & 0.16 \\
\hline
\end{tabular}

* Taxonomic status adapted from Kunte (2000)

\# Sp - Spring; Su - Summer; Em - Early monsoon; Lm - Late monsoon; Ew - Early winter; Lw - Late winter

** LSE types 1 to 5 as given in Table 4. 
Table 2. List of butterflies found outside transect area not included in statistical analysis

\begin{tabular}{ll}
\hline Family / Species * & Common name \\
\hline Nymphalidae & Tawny Coster \\
Acraea violae & Sergeant \\
Athyma perius & Southern Rustic \\
Cupha erymanthis & Painted Lady \\
Cynthia cardui & Grey Pansy \\
Junonia atliees & \\
Papilionidae & Tailed Jay \\
Graphium agamemnon & Blue Bottle \\
Graphium sarpedon & \\
Lycaenidae & Monkey Puzzle \\
Rathinda amor & Ape Fly \\
Spalgis epius & \\
Hesperidae & Dark Palm Dart \\
Astycus pythias & Malabar Spotted Flat \\
Celaenorrhinus ambareesa &
\end{tabular}

The similarity between butterfly species composition in the five landscape elements calculated from both qualitative data (Fig. 4A) and quantitative data (Fig. 4B) is given in the form of dendrograms. The overlap between both qualitative and quantitative data shows distinct patterns in the form of different clades. The overlap between different LSE types as predicted by quantitative data is lesser than that predicted by qualitative data.

\section{Discussion}

As compared to the checklist of 72 species of butterflies from the same study area (Rane \& Ranade, 2004), we could observe 69 species during our study. However, we could not observe 10 species recorded by them, but recorded seven additional species during our survey. Malabar Rose recorded by Rane and Ranade (2004) is found only in the southern and central region of the Western Ghats (between $8^{\circ} \mathrm{N}-15^{\circ} \mathrm{N}$ latitude) and has not been recorded from northern Western Ghats (Kunte, 2000). Furthermore, occurrence of Blue Nawab and Sulphur, as noted by Rane and Ranade (2004) is doubtful (K. Kunte, pers. comm.). Nonetheless, species recorded in our study as well as in the study by Rane and Ranade (2004) could be an underestimate of the total number of species. In fact, our model prediction of at least 65 species (Fig. 1) could also be an underestimate, as below a sample size of 1000 individuals the estimate of species richness can be less than $25 \%$ of the true number (Paranjape \& Gore, 1997).

The species abundance curve shows uneven distribution of butterfly species with few species being abundant and many species being rare (Fig. 2). This also explains the low evenness index in this area that ranges from as low as 0.70 to the maximum 0.90 (Tables $3 \& 4$ ). The $\log$ series may arise as a reflection of a situation where one or a few factors dominate the ecology of a community (Magurran, 1988). Therefore, it is relevant from the species abundance curve (Fig. 2) that, in our study area there could be only a few factors influencing the ecology of butterfly community. The most abundant species in the study area was Gram Blue followed by Common Four Ring (Table 1).
Table 3. Seasonal variation in species abundance, uniqueness, richness index, Shannon index and evenness index.

\begin{tabular}{lllllll}
\hline Season & S & I & US * & R & SH & E \\
\hline Spring & 23 & 143 & 0 & 4.43 & 2.42 & 0.77 \\
Summer & 31 & 82 & 8 & 6.81 & 3.09 & 0.90 \\
Early monsoon & 10 & 26 & 1 & 2.76 & 1.91 & 0.83 \\
Late monsoon & 16 & 65 & 4 & 3.59 & 1.94 & 0.70 \\
Early winter & 37 & 199 & 8 & 6.80 & 2.99 & 0.83 \\
Late winter & 26 & 118 & 2 & 5.24 & 2.91 & 0.89 \\
\hline
\end{tabular}

S - Species; I - Individuals; US - Unique Species; R - Richness; SH Shannon; E - Evenness

* - Number of species observed only in the concerned season.

Table 4. Landscape element wise variation in species abundance, uniqueness, richness index, Shannon index and evenness index. LSE types are evergreen forest (LSE 1); ragi shift cultivation (scrubland subjected to slash and burn activity) (LSE 2); riparian (LSE 3); grassland (LSE 4) and paddy fields with human habitation (LSE 5).

\begin{tabular}{lllllll}
\hline LSE type & $\mathbf{S}$ & $\mathbf{I}$ & US * & $\mathbf{R}$ & SH & E \\
\hline LSE 1 & 24 & 153 & 2 & 4.57 & 2.47 & 0.78 \\
LSE 2 & 35 & 113 & 8 & 7.19 & 3.13 & 0.88 \\
LSE 3 & 14 & 41 & 0 & 3.50 & 2.33 & 0.88 \\
LSE 4 & 25 & 72 & 1 & 5.61 & 2.83 & 0.88 \\
LSE 5 & 45 & 254 & 14 & 7.95 & 3.04 & 0.80 \\
\hline
\end{tabular}

S - Species; I - Individuals; US - Unique Species; R - Richness; SH Shannon; E - Evenness

* - Number of species observed only in the concerned season.

The seasonal distribution pattern showed two peaks of species richness and Shannon diversity index, one in summer and the other in early winter (Table 1). This pattern is consistent with that of Wynter-Blyth (1957). However, in four tropical habitats from northern Western Ghats, Kunte (1997) showed that there was no evidence of a peak in summer instead there was first peak in late monsoon and second in winter. This difference could be attributed to several factors. Three out of four study areas of Kunte (1997) are in the immediate outskirts of the Pune city and are under high influence of human interference, which was relatively less in our area. Furthermore, Kunte (1997) reported forest fires (artificial and natural) in summer in two of the study areas. Such forest fires severely affect butterfly populations (Kunte, 2001). In our study area forest fires were almost absent. Interestingly, in southern Western Ghats, Arun (2003) observed that the butterflies were more abundant in August (late monsoon); the data reveals that the species richness was more in October, November, December and February (early and late winter and spring).

Landscape element wise distribution pattern of butterflies showed high species richness and Shannon diversity in LSE 2, which comprise of ragi shift cultivation - scrubland subjected to slash and burn activity and LSE 5, which comprise of human habitation, paddy fields and scrubland. While, there was less richness and diversity in LSE 1, LSE 3 and LSE 4, which comprise of evergreen forest, stream bank and grassland. This indicates that there was more richness and diversity in the disturbed rather than undisturbed habitats (Tables $1 \& 3$ ). This 
Figure 1. Species accumulation curve of butterflies in Tamhini. Least square curve had the parameters $S_{\max }=64.6$, $\mathrm{Km}=116.8(r=0.9814)$. There could be at least 65 species in Tamhini, although we recorded 58 species in transects. Black solid line indicates theoretical curve (using Michaelis-Menten equation) and grey dots indicate actual data.

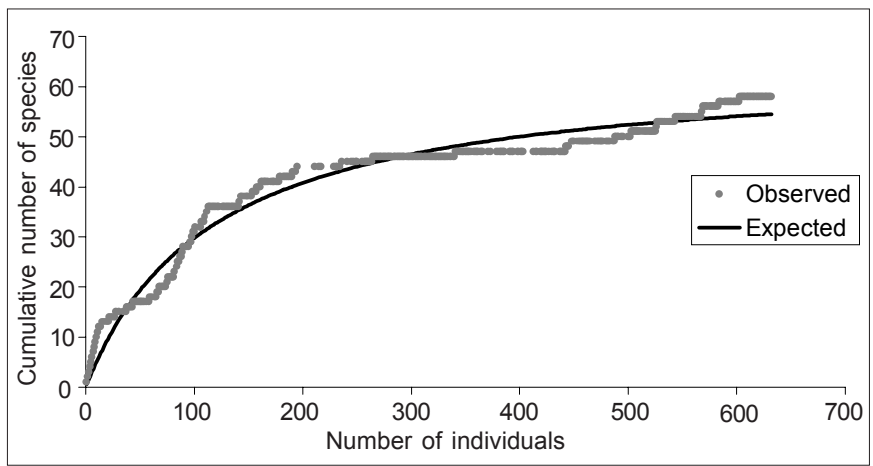

pattern contradicts with that of Kocher \& Williams (2000) and Kunte et al. (1999), however, it is consistent with that of Ramos (2000) who reported high diversity of Nymphalid butterflies at the edge of undisturbed and disturbed forest and in the disturbed forest. High diversity in LSE 5 could be attributed to various factors influencing the ecology of butterfly community. Presence of cattle dung that serves as salt reservoir for many butterfly species and restricted water source near human habitation in the dry period like summer appear to be the major factors responsible for this trend. Moreover, paddy flowering in early winter and presence of human cultivated flowering plants and fruit plants such as Mango (Mangifera indica), Jackfruit (Artocarpus integrifolia), Jamun (Eugenia jambolana), etc. acting as the nectar source also appears to influence the abundance and distribution patterns. As described earlier, LSE 5 is mixed habitats transect and as diverse niche are satisfied in this transect it shows high diversity of butterfly species (Ramos, 2000). As compared to the stream bank transect covered with evergreen canopy (LSE 1), stream bank transect without canopy (LSE 3) showed less number of species and individuals as well as less species richness and diversity. However, the evenness was more in LSE 3, which could be attributed to butterfly species like Gram Blue, Blue Pansy and Common Grass Yellow, which dominated the fauna in LSE 1.

The similarity from qualitative data (Fig. 3A) shows two distinct clusters, first comprising of spring, late winter, summer and early winter and the second comprising of early and late monsoon. The first cluster shows decreasing similarity as the number of unique species in the given season increases (Table 1). Fig. $3 \mathrm{~A}$ also depicts that the monsoon butterflies are quite distinct from that of other seasons. Such seasonality is common among butterflies and has been attributed to availability of food plants, local migration and response to adverse conditions (Kunte, 1997, 2000). One of the reasons that govern the distinct butterfly fauna in monsoon could be the heavy rain in this region that averages between 5500 and $6500 \mathrm{~mm}$. According to
Figure 2. Species abundance curve shows a log series distribution. The most abundant class of species are those that are uncommon and there are very few species that dominate the community.

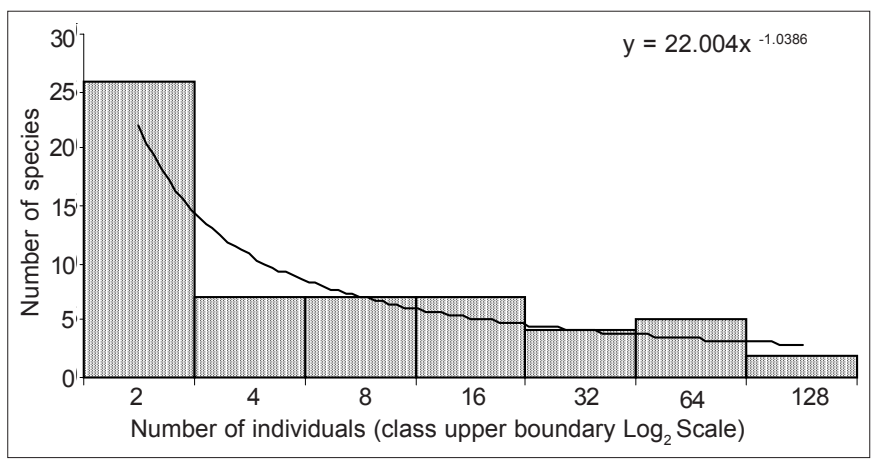

Baguette and Schtickzelle (2003), rainfall and temperature may affect butterfly distribution although the physiognomy of the habitat remains unchanged.

The qualitative trend of LSE wise dendrogram (Fig. 4A) shows decreasing similarity in the order LSE 4, LSE 1, LSE 2 and LSE 5, which is consistent with the increasing number of unique species in these LSE types (Table 4). However, LSE 3 shows the least similarity when compared with other LSE types, for reasons unknown. It may be due to small number of individuals belonging to a few species as compared to those observed in other LSE types. Moreover, this trend is independent of the number of unique species, as no species was unique to this LSE type (Table 2).

The percent similarity or species overlap across the seasons is minimum $29 \%$ and maximum $78 \%$ when qualitative (presence or absence of species) data was considered. Whereas the values drop down to minimum $10 \%$ and maximum $53 \%$ when quantitative (presence or absence of species along with the number of individuals belonging to each species) data was considered. Similar trend was also observed for the similarity across the LSE types with minimum $47 \%$ and maximum $74 \%$ when qualitative data was considered and minimum $27 \%$ and maximum $56 \%$ when quantitative data was considered. As $\beta$ diversity is low when percent similarity is high, the $\beta$ diversity is lower if qualitative data is considered, while it is high when quantitative data is considered. As the quantitative dendrograms and qualitative dendrograms also show different trends, it follows that seasonal as well as LSE wise variation in $\beta$ diversity is not only restricted to presence and absence of species but also their abundance.

Monitoring and mapping biodiversity is the first step in systematic conservation planning (Margules \& Pressey, 2000). Our study takes the initial stage of documenting biodiversity. We observed that butterfly diversity and abundance change along the seasonal gradient in each landscape type. This could be attributed to only a few factors such as rainfall, forest fires, floral composition of the area, salt and water sources, distribution of symbiotic or related animal species, etc. 
Figure 3: A dendrogram showing similarity between butterfly composition in various seasons constructed using, (A) qualitative data (presence or absence of species) and (B) quantitative data (presence or absence of species along with the number of individuals belonging to each species). Both, qualitative data and quantitative data show different clades.
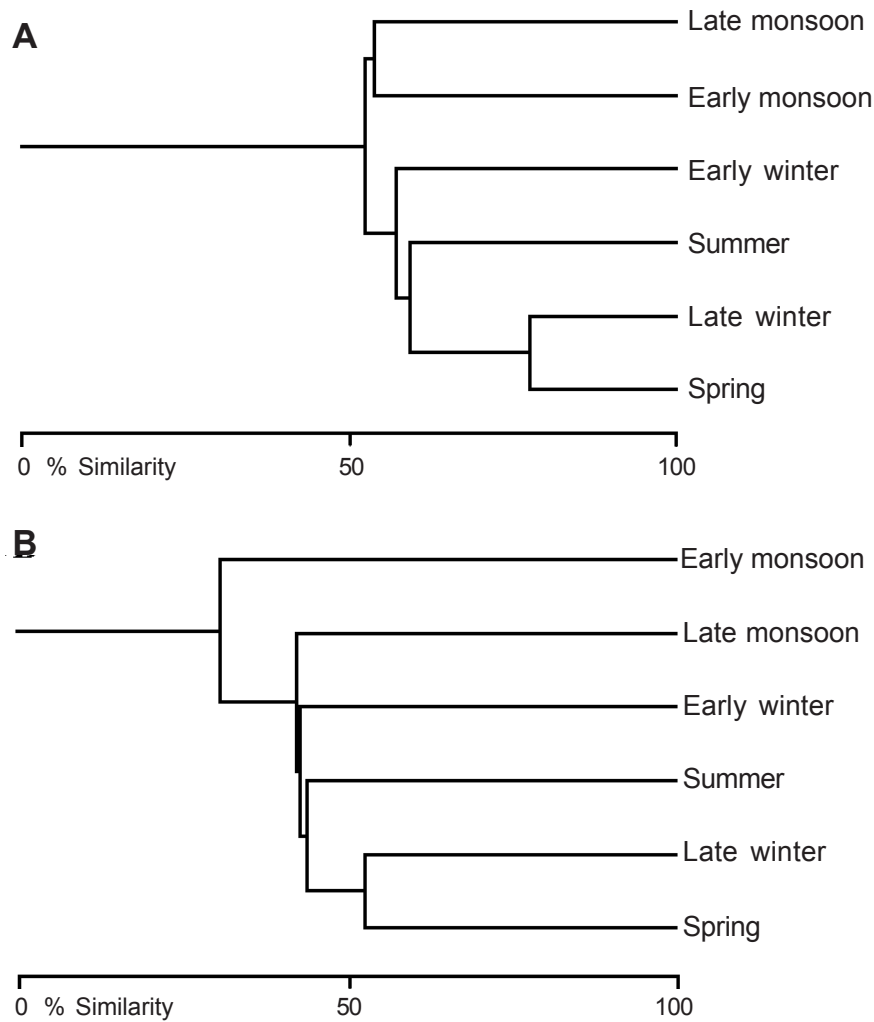

influencing the ecology of butterfly community. As dendrograms prepared by using qualitative and quantitative data revealed different trends (Figs. $3 \& 4$ ) it follows that seasonal and landscape wise variation is not only restricted to butterfly species composition but also in their abundance.

Out of a total of $50,000 \mathrm{~km}^{2}$ of primary forest in the Western Ghats, only $16 \%$ of primary forest cover exists today (Myers, 1990). This loss of biological resources has resulted in recent consciousness towards conservation of biodiversity by forming a Western Ghats Biodiversity Network (Gadgil, 1996). Being good indicators of climatic conditions as well as seasonal and ecological changes, butterflies can serve in formulating strategies for conservation (Kunte, 1997). Humans seldom hunt butterflies, however, habitat destruction, degradation, fragmentation, grazing, forest fires and applications of pesticides and weedicides can affect butterfly populations (Kunte, 2000; Mennechez et al., 2003).

A new state highway was recently constructed in the study area, which has lead to changes in land use pattern. More and more farmhouses are getting constructed. Tourism is also affecting the landscape. Deforestation, habitat destruction, degradation, fragmentation are thus common events that have
Figure 4. Dendrograms showing similarity between butterfly composition in various LSE types constructed using, (A) qualitative data (presence or absence of species) and (B) quantitative data (presence or absence of species along with the number of individuals belonging to each species). Both, qualitative data and quantitative data show different clades.
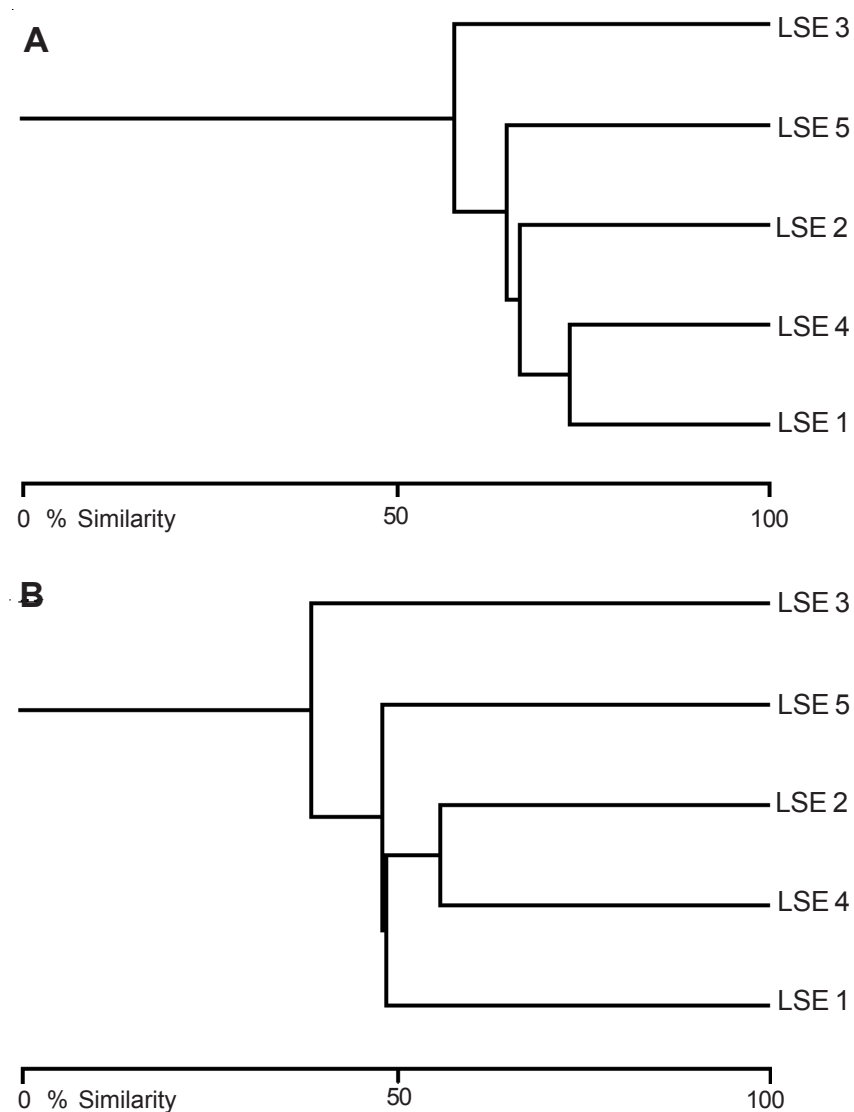

occurred in the study area. This may affect butterfly diversity and distribution in this part of the Western Ghats. These types of changes are occurring at many palaces along the Western Ghats (Jha et al., 2000). Therefore, our findings are important with respect to monitoring and defining conservation strategies as far as the biodiversity of Western Ghats is concerned.

\section{REFERENCES}

Ambrose, D.P. and D.S. Raj (2005). Butterflies of KalakadMundanthurai Tiger Reserve, Tamil Nadu. Zoos' Print Journal 20(12): 2100-2107 (plus web supplement).

Arun, P.R. (2003). Butterflies of Siruvani forests of Western Ghats, with notes on their seasonality. Zoos' Print Journal 18: 103-1006. Babjan, B. and Archana (1999). Butterflies of Krishnapuram Gram Panchayath, Alappuzha District Kerala. Zoos' Print Journal 14: 42.

Baguette, M. and N. Schtickzelle (2003). Local population dynamics are important to the conservation of metapopulations in highly fragmented landscapes. Journal of Applied Ecology 40: 404-412.

Baskaran, S. and A. Solaiappan (2002). Butterflies of Madurai city, Tamil Nadu. Zoos' Print Journal 17(10): 913-914.

Bhalodia, K., V.J. Bhuva, S.M. Dave and V.C. Soni (2002). Butterflies of Vansda National Park, Gujarat. Zoos' Print Journal 17(10): 903-904. Borkar, M.R. and N. Komarpant (2004). Diversity, abundance and habitat associations of butterfly species in Bondla Wildlife Sanctuary of Goa, India. Zoos' Print Journal 19(10): 1648-1653 (plus web supplement). 
Eswaran, R. and P. Pramod (2005). Structure of butterfly community of Anaikatty hills, Western Ghats. Zoos' Print Journal 20(8): 19391942 .

Gadgil, M. (1996). Documenting diversity: an experiment. Current Science 70: 36-44.

Gaonkar, H. (1996) Butterflies of the Western Ghats, India (including Sri Lanka): A biodiversity assessment of the threatened mountain system. Report to Centre for Ecological Sciences, IISc, Bangalore, 44pp. (Unpublished)

Gunthilagaraj, K., M.G. Kumar and P.T. Ramesh (1997). Butterflies of Coimbatore. Zoos' Print 12: 26-27.

Gunthilagraj, K., T.N.A. Perumal, K. Jayaram and M. Ganeshkumar (1998). Some south Indian butterflies. Field guide published under Project Lifescape, Indian Academy of Sciences, Bangalore, 270pp.

Jha, C.S., C.B.S. Dutt and K.S. Bawa (2000). Deforestation and land use changes in Western Ghats, India. Current Science 79: 231-238. Kocher, S.D. and E.H. Williams (2000). The diversity and abundance of North American butterflies vary with habitat disturbance and geography. Journal of Biogeography 27: 785-794.

Kunte, K. (1997). Seasonal patterns in butterfly abundance and species diversity in four tropical habitats in northern Western Ghats. Journal of Biosciences 22: 593-603.

Kunte, K. (2000). Butterflies of Peninsular India. University Press, Hydrabad, India, 254pp.

Kunte, K. (2001). Butterfly diversity of Pune city along the human impact gradient. Journal of Ecological Society 13-14: 40-45.

Kunte, K., A. Joglekar, G. Utkarsh and P. Padmanabhan (1999). Patterns of butterfly, bird and tree diversity in the Western Ghats. Current Science 77: 577-586.

McAleece, N. (1998). Biodiversity Professional Beta. The Natural History Museum and The Scotish Association for Marine Sciences.

Magurran, A.E. (1988). Ecological Diversity and its Measurement. Chapman and Hall, London, 168pp.

Margules, C.R. and R.L. Pressey (2000). Systematic conservation planing. Nature 405: 243-253.

Mennechez, G., N. Schtickzelle and M. Baguette (2003). Metapopulation dynamics of the Bog Fritillary Butterfly: comparison of demographic parameters and dispersal between a continuous and a highly fragmented landscape. Landscape Ecology 18: 279-291.

Myers, N. (1990). The Biodiversity challenge: expanded Hot Spots analysis. Environmentalist 10: 243-256.

Myers, N., R.A. Mittermeier, C.G. Mittermeier, G.A.B. da Fonesca and and J. Kent (2000). Biodiversity hotspots for conservation priorities. Nature 403: 853-858.

Nair, V.P. (2002). Butterflies of Government College Campus, Madappally, Kozhikode District, Kerala. Zoos' Print Journal 17: 911912.

Nair, V.P. (2003). Additions to the butterflies of Government College Campus, Kozhikode district, Kerala. Zoos' Print Journal 18(10): 1232. Pachpor, T., Y. Ghodke and A.D. Padhye (2001). Ant genera distribution acrosss habitats of Pune city. Journal of Ecological Society 13-14: 37-39.

Paranjape, S.A. and A.P. Gore (1997). Effort needed to measure biodiversity. International Journal of Ecology and Environmental Sciences 23: 173-183.

Radhakrishnan, C. (2000). Butterflies of Krishnapuram Gram Panchayath, Alappuzha district, Kerala - A case for revised study. Zoos' Print Journal 15: 202.

Ramos, F.A. (2000). Nymphalid butterfly communities in an Amazonian forest fragment. Journal of Research on Lepidoptera 35: 29-41.

Rane, N.S. and S.P. Ranade (2004). Butterflies of Tamhini-Dongarwadi area, Mulshi, Maharashtra. Zoos' Print Journal 19: 1411-1413.

Wynter-Blyth, M.A. (1956). Butterflies of Indian region. OxfordBNHS, Bombay, 523pp.

ACKNOWLEDGEMENT

The Western Ghats biodiversity monitoring project was partially sponsored by DST and partially sponsored by DBT. We are thankful to Prof. Madhav Gadgil for giving us the opportunity to work in this project. Dr. S.S. Kharat, Rupesh Raut, Mukul Mahabaleshwarkar, Vivek Bobade and Apurva Gajendragadakar helped us during fieldwork. We are also thankful to Drs. Milind Watve, H.V. Ghate, A.P. Gore and Mrs. S.A. Paranjape for their help and suggestions in the data analysis and preparation of this manuscript. We thank Mr. Rahul Pungaliya for his valuable suggestions in language and grammar. We are thankful to the Principal and Head of the Zoology Department of Abasaheb Garware College, for the infrastructure and facilities.

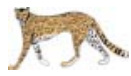

\section{Office of the Conservator of Forests \& Director Van Vihar National Park, Bhopal}

Post Box number 348, Bhopal - 462003 . E-mail: dirvvnp@sancharnet.in, Phone \& Fax- 07552674278

\section{Advertisement for Veterinarian}

The services of a Veterinarian are required for the wildlife health management of the animals of the Van Vihar National Park for the period of eleven months.

1. Number of post - One

2. Qualifications - B.V. Sc. and A.H. with Diploma in Zoo and Wildlife Management from a recognized University, and should be registered with the State Veterinary Council or Veterinary Council of India.
3. Age
- $\quad$ No age limit
4. Period
- Eleven months (to be

extended further subject to satisfactory performance)
5. Remuneration
Rs 12000/- per month

(total, no other perks)

\section{Experience \\ - $\quad$ Experience in wildlife}

health management will be desirable.

One can apply on plain paper or through e-mail. Attested copies along with original of all certificates / testimonials have to be submitted at the time of the interview. Selected candidates will be called for personal interview. For detailed information contact office of the Director, Van Vihar National Park.

\section{Conditions:}

1. The appointment will be temporary for the period of eleven months initially, which may extended subject to satisfactory performence and job requirements.

2. The asssignment will be full time and the Veterinarian will not undertake any other assignment / work during this period. 3. The Director will have the discretion to terminate services with a notice of one month. 